\title{
Thomas Hobbes: libertad, miedo y resistencia política
}

\author{
Diego Alejandro FERNÁNDEZ PEYCHAUX* \\ Academia Nacional de Ciencias de Buenos Aires \\ dfernandezpeychaux@gmail.com
}

\begin{abstract}
RESUMEN
El artículo se aboca a analizar la relación que establece el autor entre la libertad y el miedo, para luego ponerlo en referencia con la resistencia. En primer lugar, se busca estudiar la definición de libertad en el marco del debate que sostiene con el aristotelismo del siglo XVII. En segundo lugar, se establecen las conexiones entre la noción de libertad como puro acto y la resistencia política. La conclusión a la que se arriba es que aunque el miedo no constriñe la libertad ni impide la obligación, esto no supone ninguna cortapisa a la resistencia política futura.
\end{abstract}

PALABRAS CLAVE: Resistencia politica, obediencia, libertad, necesidad, determinismo politico.

\begin{abstract}
This article analyzes the relation the author establishes between freedom and fear, in order to confront it to resistance. First, it studies the definition of liberty held during the debates of XVII century Aristotelianism. Second, it establishes connections between the notion of freedom as a mere act and political resistance. The conclusion reached is that although fear does not constrain freedom nor precludes obligation, this does not imply any limitation to future political resistance.
\end{abstract}

KEYWORDS: Political resistance, obedience, freedom, necessity, political determinism.

\section{Introducción}

La definición del hombre como causa del Estado en la obra de Thomas Hobbes requiere esclarecer hasta qué punto esa determinación causal no implica asumir un determinismo que anule toda posibilidad de libertad. Si toda la realidad está constituida por movimiento y este se produce a partir de una cadena de relaciones causales necesarias, resulta pertinente preguntarse, tal como lo hicieron los lectores contemporáneos de Hobbes, si éste no termina por sostener un determinismo que niega la libertad humana, haciendo no sólo innecesario el consentimiento, sino también imposible cualquier resistencia política.

Así, dado que el autor dedica su obra a definir no sólo el derecho absoluto del soberano, sino también la libertad de los súbditos que está implícita en el pacto político, en este artículo pretendo analizar: [a] la concepción de la libertad a propósito del debate entre

\footnotetext{
* El presente texto ha sido presentado en una versión preliminar en las VII Jornadas Internacionales de Ética No Matarás, celebradas los días 29, 30 y 31 de agosto del año 2012 en la Facultad de Filosofía y Letras de la Universidad del Salvador (Buenos Aires - Argentina).
} 
Hobbes y el aristotelismo del siglo XVII; [b] las consecuencias de esa relación entre necesidad y libertad pero desde la perspectiva del soberano y la obligatoriedad de la obediencia.

En otras palabras, pretendo resolver el galimatías que Hobbes presenta cuando sostiene que la libertad responde a un grado de necesidad idéntico al que existe entre el fuego y la acción de quemar. Entonces, si la libertad es tan necesaria como que el fuego queme, ¿cuál es el espacio para libertad del hombre en el pacto político hobbesiano? ¿La resistencia política se presenta en el Leviathan como un artilugio retórico carente de vocación de facticidad o, por el contrario, supone la tangente de fuga de un discurso sobre el poder que tiende a encerrarse en un argumento circular?

\section{Libertad-necesidad}

La definición de la libertad que proporciona Hobbes en sus distintos escritos es la capacidad de moverse libre de impedimentos ${ }^{1}$. Dado que el movimiento de las pasiones se inicia en la deliberación, entonces habría que establecer cómo entiende la libertad de los juicios y su relación con la voluntad y los impedimentos que esta última encuentra. El concepto hobbesiano de libertad del hombre se establece, pues, en función de una triple relación entre el poder, la deliberación y la voluntad.

La existencia de la necesidad en las relaciones causales que gobiernan la deliberación, sostiene Hobbes, no constriñe la libertad del hombre al momento de ejercer su voluntad. De lo que se sigue que actúa libremente aquél que elije arrojar sus pertenencias al agua a fin de salvarse de un naufragio, aunque esa decisión haya sido precedida por una deliberación en la que se hace presente la relación causal necesaria entre evitar el naufragio y aligerar la carga de la nave.

En sentido contrario, el obispo Bramhall refuta a Hobbes sosteniendo que la facultad de la voluntad no es libre si está condicionada por una relación causal y necesaria.

${ }^{1}$ T. HOBBES, Leviathan with selected variants from the Latin edition of 1668, Edición, introducción y notas Edwin Curley, Indianapolis, Hackett, 1994, cap. XIV, \$2; XXI, \$2. ID., Tratado sobre el ciudadano. Trad. Joaquín Rodríguez Feo. Madrid, UNED-Varia, 2008, cap. IX, $\$ 9$. 
De lo que se sigue que el acto de arrojar la carga al agua no ha de considerarse libre, sino determinado por dicha causalidad ${ }^{2}$.

En el manuscrito Of liberty and necessity [1646] en el que Hobbes condensa sus argumentos contra la escolástica representada, en este caso, por el teólogo arminiano Bramhall, se intenta conciliar la necesidad con la libertad, lo que en su filosofía política equivale a conciliar el miedo con la libertad en el acto de consentir. El argumento central que utiliza Hobbes, que ya había utilizado tanto en De cive [1641] como en Crítica al "De Mundo" de Thomas White [1643] $]^{3}, \underline{3}$ es que la voluntad es el último acto de la deliberación y que, por tanto, mientras el hombre no haya finalizado su deliberación, continúa en la libertad de querer o no querer, aún cuando no estén en su poder las condiciones que puedan motivar una u otra vía de acción. De este modo,

[...] Es tan necesario que el fuego queme como que un hombre u otra criatura, cuyos miembros son movidos por inclinaciones, tenga su elección, es decir, la libertad de hacer lo que tiene inclinación de hacer, aunque no esté en su voluntad o poder el elegir su inclinación o elegir su elección o voluntad ${ }^{4}$.

Es decir, aún cuando el hombre se mueva por pasiones interiores que forman parte de su ser $-\mathrm{y}$ que, por tanto, causan de forma necesaria ciertos movimientos en sus pasionescomo el quemar forma parte del ser del fuego, su libertad no se ve afectada. La necesidad que la naturaleza impone al hombre afecta la deliberación de éste, pero dicha deliberación precede a la voluntad y, en consecuencia, no anula a la libertad-voluntad misma. Es absurdo, según Hobbes, sostener que el hombre carece de la libertad de volar porque esté determinado por la eficacia natural de su cuerpo. En todo caso, la imposibilidad de volar no resulta de la ausencia de libertad, sino la carencia de poderes originales o instrumentales para hacerlo ${ }^{5}$.

\footnotetext{
${ }^{2}$ J. BRAMHALL, «The Catching of Leviathan, or the Great Whale», en Leviathan: Contemporary Responses to the Political Theory of Thomas Hobbes. Thoemmes Press, 1995, 115-180. Ver también Hobbes and Bramball on liberty and necessity. Ed. V. C. Chappell. Cambridge text in the history of philosophy. Cambridge, Cambridge University Press, 1999.

${ }^{3}$ La Crítica no fue publicada sino hasta 1973, año en el que Jean Jacquot la recupera de los archivos de la Biblioteca Nacional de París.

${ }^{4}$ T. HOBBES, Libertad y necesidad, y otros escritos. Trad. B. Forteza Pujol. Barcelona, Península, 1991, 139-40.

${ }^{5}$ «Tomado universalmente, el poder de un hombre lo constituyen los medios que tiene a la mano para obtener un bien futuro que se le presenta como bueno. Puede ser original o instrumental. El poder original es un grado eminente de facultades corporales o mentales, como la fuerza extraordinaria, la apariencia, la
} 
Esta fundamentación de la compatibilidad entre necesidad y libertad implica, de forma necesaria, desarmar la distinción escolástica entre el acto voluntario, y la voluntad como facultad o potencia. Según Hobbes, la voluntad no se asimila con una facultad sino sólo en sentido figurado, ya que se fuerza el lenguaje cuando se llama facultad a la voluntad. Para el autor es ridículo «querer querer», del mismo modo que lo sería distinguir el acto de bailar de la facultad para hacerlo. Así, sin importar los condicionantes de los que deba dar cuenta el hombre al momento de deliberar hacia dónde moverse, todo acto al emanar de la voluntad del hombre ha de considerarse libre ${ }^{6}$.

[...] Cuando nosotros vemos y conocemos la fuerza que nos mueve, entonces reconocemos la necesidad, pero cuando no la vemos o no advertimos la fuerza que nos mueve entonces pensamos que no hay ninguna y que no son las causas sino la libertad lo que produce la acción. De ahí que piensen que no escoge quien escoge por necesidad; pero ellos podrían decir igualmente que el fuego no quema porque quema por necesidad ${ }^{7}$.

El acto voluntario va precedido por una deliberación de la razón que muestra al hombre de forma alternativa las razones para el apetito o la fuga ${ }^{8}$. Esa facultad de decidir se encuentra condicionada bien por la eficacia natural de los objetos $-n . b$. el poder intrínseco

prudencia, la habilidad, la elocuencia, la liberalidad, la nobleza. Instrumentales son aquellos poderes que, adquiridos mediante éstos, o por fortuna, son medios e instrumentos para adquirir otros más: riquezas, reputación, amigos, y ese secreto designio de Dios que los hombres llaman buena suerte» (T. HOBBES, Leviathan, op. cit., X, $\$ \$ 1-2)$.

${ }^{6}$ «Sea como sea, la esencia de la distinción de Su Señoría es que un acto voluntario puede ser hecho por coacción, es decir, a las malas, pero querer éste u otro acto sólo es posible por atracción, o por las buenas. Ahora, viendo que los buenos medios, las atracciones y las incitaciones producen las acciones que producen tan necesariamente como los malos medios y las amenazas, se sigue que querer puede llegar a ser algo tan necesario como lo que se hace por coacción. De modo que estas distinciones entre actus imperatus y actus elicitus no son más que palabras y no tienen ningún efecto contra la necesidad» ( $\mathrm{T}$. HOBBES, Libertad y necesidad, op. cit., 158).

${ }^{7}$ Ibid., $156-7$.

${ }^{8}$ De ahí que quien desea una cosa o se dispone a hacer algo que le parece bueno, al ver el mal que a ello va unido y que antes no veía, es rechazado y huye; de nuevo, al ver en la misma serie un bien mayor, lo desea otra vez, y así alternativamente, según se vean como preponderantes los bienes o los males, hace u omite lo que primero había deseado hacer. Y esto se llama "deliberar". La deliberación no es sino la alternancia del apetito y la fuga. El nombre de deliberación parece que se asignó a ese movimiento de alternancia, porque debido a él la libertad de aquel que así es llevado de un lado a otro se determina o se quita, pues no dejan de sucederse alternativamente el apetito y la fuga hasta que -porque se actúa o porque se pierde la ocasión- desaparece la libertad de hacer u omitir. Y así el fin de la deliberación es la deposición de la libertad» (T. HOBBES, «Crítica al De Mundo de Thomas White (Capítulo XXX): Problema $5^{\circ}$ del Diálogo $3^{\circ}$ », en Libertad y necesidad, y otros escritos, 89-121. Trad. B. Forteza Pujol. Barcelona, Península, 1991, 111-2). 
del hombre funciona como una especie de eficacia natural de los objetos-, bien por «una imaginación alternada de las buenas y malas consecuencias de una acción»9.

Un factor importante a tener en cuenta para comprender el argumento hobbesiano sobre la libertad de la voluntad radica en advertir que para el autor no se dan decisiones en las que se acepta, niega o renuncia a algo de una vez y para siempre. Esto se debe a que la deliberación que precede a la voluntad no alterna entre un bien apetecible en su totalidad ajeno de todo mal, y un mal aborrecible en su totalidad ajeno de todo bien. En su lugar, la razón al deliberar muestra al hombre, cuanto mucho, series en las que están ligados factores presentes y futuros tanto que disgustan como aquellas que placen. De ahí que el hombre no decida entre el bien o el mal, sino entre situaciones con diversos niveles de incertidumbre en sus alternativas presentes y futuras. De este modo, aún cuando esa cadena causal determine el último acto de la deliberación, dicha determinación no posee un carácter unívoco, ya que depende de cómo realice cada hombre el cálculo de costebeneficio, anticipando esa larga cadena de consecuencias ${ }^{10}$. Empero, cuando la voluntad actúa, aduce Hobbes, se cierra el ciclo deliberativo y pierde la capacidad de volver a decidir en relación con dicha situación sin incurrir en el absurdo de negarse a sí misma. En Leviathan el eje del pacto político se asienta en este punto -ie. una suerte de obligación de no contradicción ${ }^{11}$.

De este modo, los sujetos se encuentran ante una disyuntiva. Por un lado, la necesidad de realizar una proyección en la que se anticipen las posibles derivas de los acontecimientos y tomar una decisión basados en un cálculo individual sobre posibles series de acontecimientos futuros. Por el otro, saben que para no entrar en contradicción una vez ejercida la libertad, no pueden desdecirse. En otras palabras, los sujetos se verán determinados para decidirse en favor de aquellas series menos malas, contrayendo la obligación de mantener su decisión aún a riesgo de estar calculando de forma equivocada o de estar siendo engañados. Si en este caso, y anticipándonos en parte al próximo apartado, se reemplazaría el término determinación, por el de extorsión, ya que la decisión de los sujetos, además de ser definitiva, se toma bajo la premura del miedo y en condiciones de incertidumbre. Lo cual viene a significar que Hobbes habría conciliado la libertad con

\footnotetext{
${ }^{9}$ T. HOBBES, Libertad y necesidad, op. cit., 165.

${ }^{10}$ T. HOBBES, Leviathan, op. cit., VI, \57-8.

${ }^{11}$ Ibid., XIV, $\$ 7$.
} 
la necesidad, sólo para brindar una mejor apariencia al acto de sumisión del hombre a la realidad natural o política.

No obstante, en este artículo quisiera hacer explícitos dos matices a esta lectura de Hobbes. El primero y fundamental consiste en apreciar la distancia que media entre la voluntad explícita y la tácita. El criterio de no contradicción no se aplica sobre la primera -ie. explicita-, sino sólo sobre la segunda $-i e$. la voluntad tácita-, ya que ésta última encierra el contenido auténtico de la acción voluntaria. «La realización de actos voluntarios -afirma Hobbes- tiene por objeto la consecución de algún bien para sí mismo. Y, por tanto, hay algunos derechos que ningún hombre, ni mediante palabras ni mediante cualquier otro signo, ha dado a entender que los ha abandonado» ${ }^{12}$. Estas palabras del autor vienen a significar que no hay signo que pueda contradecir la voluntad tácita siempre presente e autopreservación. De ahí que en el acto de sumisión estén «implicadas nuestra obligación y nuestra libertad», afirma el autor en el capítulo XXI del Leviathan. Esta preeminencia de la voluntad tácita sobre la explícita pone a buen recaudo la libertad de los individuos de los intentos por engañarla o de los movimientos futuros imposibles de calcular.

El segundo matiz que debería hacerse explícito consiste en que el factor de incertidumbre introducido por el cálculo de probabilidad en series de eventos alternativos expande la noción de libertad. Los hombres son tenidos en cuenta como agentes y no como una mera bola de billar que se mueve en función de las interacciones mecánicas. La conciencia que el hombre adquiera de las determinaciones internas y externas no altera el hecho de que sea la deliberación aquella que deba informar a la voluntad -n.b. entendida como elección-. De lo que se sigue que el resultado de la acción sea siempre incierto. La modulación de la relación entre libertad y necesidad hace posible sostener que el determinismo desaparece en favor de la libre elección ${ }^{13}$. Para Hobbes, la determinación causal de toda la realidad no comporta asumir la desaparición de la libertad como el acto humano en el que emerge la posibilidad de independizarse al emprender acciones que Dios nos les manda hacer, aún cuando ese mismo Dios cause todas sus acciones ${ }^{14}$. En

\footnotetext{
${ }^{12}$ Ibid, XIV, $\$ 8$.

${ }^{13}$ D. van MILL, 1995. «Hobbes's Theories of Freedom». The Journal of Politics 57 (2) (Mayo 1): 443-459. GERT 1996, pp. 157-174).

${ }^{14}$ T. HOBBES, Leviathan, op. cit., XXI, $₫ 4$.
} 
última instancia, la fuerza de las pasiones puede hacer deseable una acción aún cuando ésta sea racionalmente reprobable.

El Leviathan se figura como un intento por convencer a los lectores de que, ante el miedo a la muerte, la decisión más racional es la constitución de un soberano con el poder suficiente para dirigir dichos miedos hacia una única dirección -i.e. su espada-, eliminando de ese modo la mutua voluntad de agresión. Empero, el autor no deja de remarcar en sus obras que no existe el gobierno ajeno a los inconvenientes presentes y futuros. La libertad del consentimiento emerge, pues, como la consideración individual e irreemplazable en la que cada hombre somete a escrutinio sus propias pasiones y decide cuál alternativa puede soportar mejor. En el mismo sentido Carl Schimitt apunta que «del Estado así construido por obra del hombre y de la condición de paz "civil" lograda por él, Hobbes no hace en lo absoluto un paraíso terrenal. [...] Estado y revolución, Leviathan y Behemoth, están ambos siempre presentes y son potencialmente efectivos» ${ }^{15}$. Leer el Leviathan de Hobbes como las pinceladas maestras del retrato de una nueva Atlántida supondría percibir en sus páginas el propósito de abolir la mecánica del mundo.

\section{Libertad-miedo}

A la afirmación sobre la compatibilidad entre necesidad y libertad le sigue de forma lógica la compatibilidad entre miedo y libertad. En The Questions concerning Liberty, Necessity, and Chance se sostiene que la verdadera libertad «no consiste en determinarse a sí mismo, sino en hacer aquello a lo que la voluntad está determinada» ${ }^{16}$. De este modo, no queda lugar a dudas sobre la relación poder-libertad. El problema de la libertad no estriba en lo querido, sino en las posibilidades de realizar las acciones conducentes a obtener el objeto deseado. Sin embargo, esta relación de la libertad con el poder no agota el problema de la libertad. Hobbes no se limita a presentar las barreras exteriores como los únicos instrumentos capaces de constreñir la voluntad del hombre. El argumento central de su obra política

\footnotetext{
${ }^{15}$ SCHMITT, Carl. El Leviatán en la doctrina del Estado de Thomas Hobbes. Biblioteca de Ética, Filosofía del Derecho y Política, nro. 109. Mexico D.F., Univ. Autónoma Metropolitana, 1938 [2008], 96.

16 «The Questions concerning Liberty, Necessity, and Chance, clearly stated and debated between Dr. Bramhall, Bishop of Derry and Thomas Hobbes of Malmesbury», en English Works of Thomas Hobbes of Malmesbury. London, J bohn, 1839, vol. V, p. 35. [Traducción propia].
} 
consiste en denunciar la hipocresía de aquellos que obvian recordar que sus propios actos, y no los de la autoridad soberana, limitan la libertad natural.

En Critique du De mundo de Thomas White y Leviathan se presentan las siguientes definiciones de voluntad, en las cuales se evidencia la profunda relación que se establece entre el ejercicio de la voluntad y la libertad ${ }^{17}$.

La voluntad es el último acto de quien delibera; este último acto, si se trata de un apetito, es «voluntad de hacer», y si se trata de una aversión, es «voluntad de no hacer». Y así como se entiende que no hay voluntad en aquel que todavía delibera, también se entiende que no hay deliberación en aquel que ha querido ${ }^{18}$.

«En la deliberación, el último apetito o aversión, que precede inmediatamente a la acción o a la omisión es lo que llamamos VOLUNTAD, el acto, no la facultad, de querer, y las bestias que poseen deliberación, han de poseer también, necesariamente, voluntad. [...] Por lo tanto, la voluntad es el último apetito en el proceso deliberador» ${ }^{19}$.

[...] Un hombre libre es aquél que, en aquellas cosas que puede hace en virtud de su propia fuerza e ingenio, no se ve impedido en la realización de lo que tiene voluntad de llevar a cabo ${ }^{20}$.

Si la voluntad es el acto -y no la potencia- por medio del cual se suspende la deliberación y el hombre queda obligado, es dado preguntar cómo es posible que el hombre se imponga a sí mismo un impedimento a su libertad. En otras palabras, qué criterio emplea Hobbes para equiparar un hombre encadenado -i.e. impedimentos externos- a otro que ha decidido no moverse -i.e. impedimentos internos-. Asimismo, ¿esa identificación entre el encadenado y el que decide no moverse es funcional en todo momento, u opera como una analogía sólo bajo determinadas circunstancias?, ya que, como sostiene Hobbes,

\footnotetext{
${ }^{17}$ J. HARMAN, 1997. «Liberty, Rights, and Will in Hobbes: A Response to David Van Mill». The Journal of Politics 59 (3): 896-7. M. GOLDSMITH, 1989. «Hobbes on Liberty». Hobbes Studies 2 (1): 23-39.

${ }_{18}$ T. HOBBES, Crítica al De Mundo de Thomas White, op. cit., 112.

${ }^{19}$ T. HOBBES, Leviathan, op. cit., VI, $\$ 53$.

${ }^{20}$ Ibid., XXI, $\$ 2$.
} 
«mientras vivamos aquí, no habrá tal cosa como una perpetua tranquilidad de ánimo, ya que la vida misma es movimiento» ${ }^{21}$.

Antes de proseguir realicemos una breve recapitulación de los argumentos presentados. En Leviathan, se define la libertad política como la ausencia de impedimentos externos. Pero cuando el autor considera la libertad de los súbditos en el capítulo XXI de la misma obra, ésta parece limitada más por la propia voluntad que por los impedimentos externos. Para decirlo con una imagen elocuente, imaginemos que el súbdito no limitaría sus movimientos por la existencia de un precipicio más allá de los confines de la seguridad del Estado -límite externo a su movimiento-, sino por su decisión de no traspasar dichos límites; decisión que está determinada, a su vez, por el miedo que le infringe el precipicio $^{22}$. En este sentido, el hombre que decide no moverse lo hace libremente, pero su decisión comporta un límite a sus acciones que se constituye como un impedimento $\operatorname{artificial}^{23}$.

Pero del mismo modo que los hombres, a fin de conseguir la paz y la conservación de sí mismos, han fabricado un hombre artificial al que llamamos Estado, así también han fabricado una serie de ataduras artificiales, llamadas leyes civiles, que los hombres mismos, mediante convenios mutuos, han prendido, por un extremo, a los labios del hombre o asamblea a los que han entregado el poder soberano, $y$, por el otro, a sus propios oídos. Estas ataduras, aunque débiles en sí mismas, pueden ser duraderas, no porque sea difícil romperlas, sino por el peligro que se derivaría de hacerlo ${ }^{24}$.

La intención de Hobbes al presentar la compatibilidad entre miedo-libertad y libertadnecesidad consiste en sostener que el hombre no pierde su libertad a causa de las determinaciones que informan la deliberación previa a la voluntad. De este modo, el consentimiento dado a un soberano por institución o despótico, tiene la misma fuerza y

\footnotetext{
${ }^{21}$ Ibid., VI, $\$ 58$.

22 G. MACCALLUM, "Negative and positive liberty", en Politics, Pbilosophy and Society, Fourth Series, ed. P. Laslett, W.G. Runciman, Q. Skinner. Oxford, Basil Blackwell, 1981, 174-193. F.OPPENHEIM, Political Concepts, a Reconstruction. Chicago: University of Chicago Press, 1981, 53-95.

${ }_{23}$ M. GOLDSMITH, op. cit., 28-30. A. BRETT, Liberty, Right and Nature: Individual Rights in Later Scholastic Thought. Cambridge: Univesity Press, 1997, 227-34.

${ }^{24}$ T. HOBBES, Leviathan, op. cit., XXI, $₫ 5$.
} 
legitimidad, ya que tanto en un caso como en el otro el miedo no impide la acción voluntaria - i.e. libre -25 .

La opinión de Skinner es que cuando Hobbes elimina en Leviathan los impedimentos internos como fuentes de restricción de la libertad, está contrariando la base misma de la definición republicana tradicional del hombre libre. En otras palabras, el hecho de que el miedo y la libertad sean compatibles hace imposible concebir la libertad como independencia, ya que el soberano poderoso no sólo lo protege sino que también tiene el poder de obligarlo o limitarlo a elegir sus propios fines individuales. Así, el mero hecho de la existencia de un poder despótico limita esa independencia y, por tanto, la libertad del hombre, convirtiéndolo en un esclavo. La libertad del súbdito sería igual a la extensión de la cadena que le sujeta a su soberano. La condición de un súbdito en un Estado despótico no difiere de la del esclavo en tanto que está encadenado a un poder al que ha consentido, determinado por una situación de miedo ${ }^{26}$. De acuerdo con el convenio hobbesiano, ese súbdito renuncia a su derecho y con ello a su poder, por lo tanto, no puede decirse que sea libre o no para abandonar su obediencia, sino tan sólo que no tiene poder para hacerlo ${ }^{27}$.

Empero, un análisis comparado entre las tres obras principales de Hobbes muestra que la lectura de Skinner en relación con los límites de la libertad pasa por alto ciertos matices que se desprenden del análisis fáctico presente en dichos textos. En concreto, Skinner no advierte que al igual que la determinación de la voluntad puede matizarse, la determinación del consentimiento por el miedo también. En última instancia «los hombres pueden hacer muchas cosas que Dios no les manda hacer» ${ }^{28}$. O, lo que es lo mismo, la compatibilidad entre miedo-libertad viene a ser sólo la consciencia de que el móvil del hombre en el estado de naturaleza es el miedo, aunque esto no conlleve asumir una legitimidad irrevocable y unidimensional de todas las acciones concretas motivadas por dicha pasión. Así, aún cuando el miedo insufle a la decisión del hombre una necesidad idéntica a la que existe entre la naturaleza del fuego y el que éste queme, dicha decisión no está unidireccionalmente predeterminada y legitimada. Por lo tanto, la cuestión de la

\footnotetext{
${ }^{25}$ Ibid., XX, $\$ 2$.

${ }^{26}$ Q. SKINNER, Hobbes and Republican Liberty. Cambridge, Cambridge University Press, 2008, 129, 152157.

${ }^{27}$ Q. KINNER, Visions of Politics. Volumen 3: Hobbes and Civil Science. Cambridge, Cambridge University Press, 2002, 210-4.
} 
libertad política deja de ser sólo una cuestión de poder, como en la libertad natural, para convertirse también en una cuestión de consentimiento y seguridad efectiva.

Por todo ello, la primera enmienda a esta lectura de Skinner pasaría por señalar que está omitiendo la distinción hobbesiana entre la libertad corporal y la libertad natural o derecho natural ${ }^{29}$. Podría decirse que es indefendible una lectura en la que la libertad del estado de naturaleza tenga la misma medida que en la sociedad civil ${ }^{30}$. En última instancia, el argumento central de sus tres obras políticas es que mientras el miedo al bandido hace que perdamos la libertad en el caos de la desconfianza mutua y la guerra, el miedo al soberano, por su parte, aumenta la libertad. Esta libertad política tiene las mismas condiciones de posibilidad que en el estado de naturaleza -i.e. alcanzar la seguridad a través de la disposición de poderes-medios que prevengan el ataque de otros-, aunque sus posibilidades reales sean diametralmente distintas. La insistencia hobbesiana sobre la inutilidad del derecho a todo es el punto clave de esta diferenciación ${ }^{31}$.

La segunda enmienda a la crítica de Q. Skinner es que en el capítulo XXI de Leviathan, tal como ya apuntamos, se sostiene que si «en el acto de nuestra sumisión van

${ }^{28}$ T. HOBBES, Leviathan, op. cit., XXI, \4.

29 A. BRETT, op. cit., 227-33. D. D. RAPHAEL, "Hobbes". En Conceptions of Liberty in Political Philosophy, ed. Zbigniew Pelczynski y John Gray, Londres, Athlone, 1984, 27-38. J. R. PENNOCK, 1960. «Hobbes's Confusing "Clarity"--The Case of "Liberty"». The American Political Science Review 54 (2) (Junio): 428-436.

${ }^{30} \mathrm{La}$ referencia a las distintas medidas de la libertad no pretende establecer una posición en la polémica sobre el tratamiento hobbesiano de la libertad como un espacio. M. GOLDSMITH niega que el concepto de libertad de Hobbes pueda ser utilizado desde una perspectiva espacial (op. cit., 23-39). A. BRETT, por su parte, afirma que aún cuando en De Cive se utilicen ejemplos que dan a entender esa concepción espacial, esto no implica su corporeidad (op. cit., 224-5).

31 Como se menciona más adelante en este artículo, en sentido estricto para Hobbes no existe la justicia en el estado de naturaleza. Ante esta ausencia, el derecho a todo se manifiesta como inútil. La ausencia del deber de no tomar lo deseado, incisa J. Finnis, tiene como corolario el que nadie tenga un derecho (J. FINNIS, Natural Law and Natural Rights. Oxford: Clarendon Press, 1980, 208). Hobbes no ignora esta precisión y en Elements afirma que: «Pero el derecho de todos los hombres a todas las cosas no es, en efecto, mejor que si ningún hombre tuviese derecho a nada. Pues el derecho que tiene un hombre le resultará de poca utilidad y beneficio cuando otro tan fuerte o más fuerte que él tenga derecho a lo mismo» (T. HOBBES, Elementos de Derecho Natural y Politico. Trad. Dalmacio Negro Pavón. Ciencias sociales. Madrid: Alianza Editorial, 1979, I, XIV, \$ 10). En un sentido similar se pronuncia Hobbes en De Cive: «Pero no les fue útil en absoluto a los hombres el que tuvieran de este modo un derecho común a todo. Pues el efecto de tal derecho viene a ser como si no existiera derecho alguno» (T. HOBBES, Tratado sobre el ciudadano, op. cit., I, \$11). La inutilidad se suscita como el resultado esperable de una situación en la que dos individuos tienen derecho sobre un mismo objeto, pero cuyo poseedor efectivo se establece a partir de cotejar la potencia efectiva de los respectivos poderes. El derecho a todo hobbesiano no incluye un dominio justo y excluyente de los demás sobre un determinado bien o individuo, sino tan sólo una capacidad o facultad de hacer uso de algo. La respuesta de Hobbes al ejemplo clásico de la posesión de los asientos de un teatro es que los hombres disponen del derecho a sentarse en cualquier asiento, mientras tengan el poder de desocuparlo y resistir cualquier intento ulterior de ser expulsados. Por lo tanto, su 
implicadas nuestra obligación y nuestra libertad» los súbditos siempre tendrán el derecho -i.e. libertad- de defender su vida y sus propios cuerpos contra quienes los invaden, aún cuando dicha invasión sea legal. Por lo tanto, no puede concluirse, como hace Skinner, que la libertad entendida como el poder de movimiento desaparezca a partir de la celebración del pacto hobbesiano.

Las razones que sustentan esta enmienda a la lectura de Skinner, además de las brindadas hasta aquí, son dos características constitutivas del convenio. En primer lugar, la renuncia al derecho a todo no se traduce en una transferencia del derecho entendido como libertad natural. Del mismo modo que el soberano no adquiere un poder del que no tenía disposición antes del pacto, tampoco el súbdito aliena de forma absoluta ese mismo poder. Esta renuncia no crea derechos, sino que hace efectivos los de unos para garantizar los de otros ${ }^{32}$. En segundo lugar, y estrechamente relacionado con lo anterior, el pacto no comporta una renuncia a la auto-defensa contra la fuerza, sino sólo al ejercicio del derecho a todo. Por lo tanto, la libertad en la sociedad civil tiene como límite la justicia, porque sólo se está obligado a hacer aquello que es justo, es decir, lo pactado.

Resultará manifiesto que todo súbdito tiene libertad en aquellas cosas cuyo derecho a ellas no puede transferirse mediante un convenio. Ya hemos tratado antes, en el capítulo 14 , que aquellos convenios en los que un hombre renuncia a la defensa de su propio cuerpo son inválidos ${ }^{33}$.

La definición de libertad de Leviathan, al igual que la de De cive, justifica que el hombre siga siendo libre tras el pacto político porque la protección del poder soberano constriñe su derecho inútil a todo, aunque amplíe las posibilidades concretas de auto-preservación. Es decir, la libertad bajo las leyes civiles se hace posible en una dimensión impensable para el estado de guerra ${ }^{34}$. Por un lado, porque en la medida en que el soberano administre sabiamente su poder, hace posible la libertad en lugar de eliminarla. Por otro lado, debido

derecho a todos los asientos le brinda la misma seguridad jurídica que obtendría si no tuvieran ningún derecho.

${ }^{32}$ T. HOBBES, Leviathan, op. cit., XIV, $\$ 6$.

${ }^{33}$ Ibid., XXI, \$11.

34 P. PETTIT, 2002. «Keeping Republican Freedom Simple: On a Difference with Quentin Skinner». Political Theory 30 (3) (Junio): 339-356. 
a la equiparación de la obligación con lo pactado, el absolutismo se extiende sólo hasta los límites de los términos de su uso correcto ${ }^{35}$. Por consiguiente Hobbes afirma que:

Pues si tomamos la palabra libertad en su sentido más propio, esto es, en el sentido de libertad corporal, libertad de cadenas y prisión, sería sobremanera absurdo que los hombres reclamaran para sí, como de hecho hacen, una libertad de la que, como es evidente, ya están disfrutando. Y si consideramos la libertad como exención de cumplir las leyes, no es menos absurdo que los hombres reclamen, como también hacen, esa libertad en virtud de la cual todo los demás hombre pueden ser dueños de sus vidas ${ }^{36}$.

La posición del autor tanto en Leviathan como en Of Liberty and Necessity, consiste en que no puede considerarse a un hombre menos libre por el hecho de depender de la voluntad de otro a raíz de un pacto celebrado, especialmente si éste lo ha hecho libremente. Lo que afecta realmente la libertad es que un hombre se vea impedido de preservarse, tanto en el estado de naturaleza como en la sociedad civil ${ }^{37}$. De este modo, aún cuando el hombre renuncie a su derecho a todo, mantiene un interés inderogable sobre la seguridad de su propia persona ${ }^{38}$. Esta limitación intrínseca a las posibilidades del consentimiento evita, según lo mencionado anteriormente, el peligro de que la obligación surja del engaño o del error en la deliberación sobre esas largas series de causas, y que lleve al hombre a consentir un régimen que implique su encadenamiento.

Por libertad quiero decir que no exista ninguna prohibición innecesaria respecto a cualquier hombre de una cosa que le esté permitida por la ley natural; es decir, que no se restrinja la libertad natural, salvo en lo necesario para el bien de la república; de modo que hombres sinceros no caigan en el peligro de las leyes como en trampas, sin darse cuenta ${ }^{39}$.

Dicho esto, podemos volver a la duda inicial de este apartado sobre la equiparación de un hombre encadenado con otro que ha decidido no moverse. La respuesta a la misma

35 D. J. C. CARMICHAEL, 1990. «Hobbes on Natural Right in Society: The "Leviathan" Account». Canadian Journal of Political Science / Revue canadienne de science politique 23 (1) (Marzo): 3-21.

36 T. HOBBES, Leviathan, op. cit., XXI, \$6.

${ }^{37}$ Ibid., XXI, \$8; Elementos, op. cit., I, IV, \$2; Tratado del ciudadano, op. cit., IX, \$9.

${ }^{38}$ J. HARMAN, op. cit., 900-1. A. BRETT, op. cit., 219. M. OAKESHOTT, Hobbes on Civil Association. Introd. P. Franco. Indianapolis, Liberty Fund, 2000, 53-81.

${ }^{39}$ T. HOBBES, Elementos, op. cit., II, IX, \4; cfr. Leviathan, op. cit., XXI, $\$ 12$. 
consiste en afirmar que las limitaciones intrínsecas al consentimiento dejan entrever cómo no pueden identificarse ambas situaciones de forma absoluta. Mientras el encadenado pierde su libertad hasta que es liberado por otro, el que ha decidido no moverse rinde parte de su libertad natural a raíz de una decisión informada por su recta razón y sus pasiones, que le hacen descubrir la conveniencia de esa inmovilidad. Pero esta rendición de la libertad se traduce en obstáculos artificiales que bajo circunstancias particulares desaparecen, recuperando su libertad-derecho natural originario.

Digamos una vez más que el consentimiento dado por un súbdito al poder soberano está contenido en estas palabras: Yo autorizo o asumo todas sus acciones. Y en esta declaración no hay restricción alguna de la propia libertad natural que se tenía antes; pues cuando yo permito al soberano que él me mate, no estoy obligándome a matarme yo mismo cuando él me lo ordene $e^{40}$.

La principal diferencia entre estar preso y consentir la no resistencia es que si la libertad queda relacionada con la justicia, pareciera que el límite de esta se mide en función de un equilibrio entre coerción y acción voluntaria ${ }^{41}$. Esta libertad de disentimiento, reconocida por Hobbes, manifiesta cómo la libertad en la sociedad civil no se mide sólo en función de las barreras que las leyes del soberano imponen al individuo, sino también por una consideración individual sobre la justicia -nb. evaluar si lo que ordena el soberano coincide con la voluntad originaria del pacto- y la conveniencia de esa leyes. En el estado de naturaleza, por el contrario, la libertad del hombre sigue estando referida sólo a la posibilidad de movimiento en relación con el propio poder ${ }^{42}$.

El hombre, bajo la autoridad del soberano civil pierde, por voluntad propia, su libertad natural en todos aquellos aspectos en los que la ley le exija un comportamiento determinado. Empero, como se ha venido apuntando, no hay ley donde no hay -o no pudo- haber convenio. De lo que se sigue que el hombre es libre respecto de las leyes civiles tanto si estas no ordenan nada, como si ordenan algo que no se ha pactado, e.g. dejarse matar, no consumir alimento, etc.

\footnotetext{
${ }^{40}$ Ibid., XXI, \$14.

${ }^{41}$ G. NEWEY, Hobbes and Leviathan. Londres: Routledge, 2008, pp. 87-105. K. HOEKSTRA, "The de facto Turn in Hobbes's Political Philosophy”. En Leviathan After 350 Years, ed. T. Sorell y L. Foisneau. Oxford, Clarendon Press, 2004, 33-73. D. CARMICHAEL, op. cit., 3-21.
} 
Ahora bien, del mismo modo en que Hobbes defiende la similitud del convenio político entre los Estados de origen despótico y los surgidos de la institución, también admite que ambos pueden devenir en una situación en la que las pasiones de los individuos -sean súbditos o soberanos- subviertan las condiciones de posibilidad de la paz. Ante tal acontecimiento, el sujeto que ha decidido no moverse puede encontrar que lo que empezó siendo voluntario ha devenido en una imposición exterior cuando, al descubrir la trampa de la que ha sido víctima, intente echarse a andar y se dé cuenta de que lo han encadenado. La facticidad del poder de preservación no se agota, entonces, en los aspectos inherentes del hombre, sino que entran a jugar otros factores externos.

Ya pueden estar los hombres todo lo imbuidos que se quiera de opiniones contrarias a la paz y al régimen civil; ya pueden considerarse provocados hasta el límite por las injurias y las ofensas de los que tienen autoridad; si la esperanza de vencer no existe o no es lo bastante grande, no habrá sedición alguna; todos disimularán y preferirán soportar cosas graves antes que otras más graves todavía. Para que se dé esta esperanza son necesarias cuatro cosas: número, instrumentos, mutua confianza y jefes ${ }^{43}$.

Bajo estas circunstancias el impedimento para quitarse la carga de las injurias del soberano no es una decisión voluntaria, sino un diferencial de poder individual que constriñe al hombre su posibilidad de resistirse, cuando ya ha decidido que la situación es tan miserable e insoportable como para considerar dicha opción. La diferencia entre esta instancia y la anterior es que la imposibilidad fáctica de la resistencia civil le muestra al hombre que la cortapisa de su libertad no es artificial, sino externa.

En esta situación, aduce Skinner, se evidencia cómo Hobbes anula de facto la libertad al sostener que la imposibilidad de ejecutar una acción no está fundada en la ausencia de libertad, sino de poder. Así, la carencia de poder hace irrelevante la pregunta sobre la libertad ${ }^{44}$. De este modo, si la interpretación de Skinner es correcta, la pregunta sobre la libertad carece de relevancia, de la misma manera que lo hace el hablar de justicia en el estado de naturaleza. El inconveniente de esta lectura es que, aún cuando esté en lo

\footnotetext{
${ }^{42}$ D. MILL, op. cit., 448-51.

43 T. HOBBES, Tratado sobre el ciudadano, op. cit., XII, $\$ 11$.

${ }_{4}$ Q. SKINNER, Visions of Politics, op. cit., 214-5. F. C. HOOD, 1967. «The Change in Hobbes's Definition of Liberty». The Philosophical Quarterly 17 (67) (Abril): 150-163.
} 
cierto y la pregunta sobre la libertad desaparezca, también ha de reconocerse que Hobbes reconoce el derecho y la libertad de romper sus ataduras a los hombres que están encadenados.

Pero si un hombre es encerrado en prisión, o es encadenado, o no se le concede la libertad corporal, no podrá asumirse que está obligado a la sujeción en virtud de pacto alguno y, por lo tanto, le estará permitido, si puede, escapar por todos los medios a su alcance $^{45}$.

Empero, a partir de la diferenciación entre la libertad corporal y la libertad natural, referido más arriba, es posible introducir algunas matizaciones que, sin contradecir las implicaciones que tiene la concepción de libertad vertida en Leviathan, sirven para modular el mito del absolutismo del monstruo de Malmesbury. En primer lugar, la defensa de la legitimidad del origen despótico del poder soberano no rebate el hecho de que Hobbes afirme que una situación de dominación como la que se está describiendo sea sostenible a mediano y largo plazo. Los intereses del soberano y los de los súbditos no pueden permanecer discurriendo con tal disparidad sin llegar a anularse mutuamente.

En cuanto a otros beneficios [...] referentes al bienestar y al deleite, como las riquezas superfluas, deben pertenecer al soberano tanto como al súbdito y al súbdito tanto como al soberano. [...] Por tanto, si el soberano no actúa de manera que las personas privadas pueden disponer de medios, tanto para defenderse a sí mismas, como para defender lo público, no existirá el tesoro común o soberano. Por otra parte, si no existiera un tesoro común y público en manos del poder soberano, las riquezas privadas de las personas servirían más para llevarlas a una situación de confusión y guerra que para protegerlas o mantenerlas ${ }^{46}$.

El carácter insostenible de estas situaciones a largo plazo se debe, a su vez, a que la garantía de la libertad individual por parte del Estado no se restringe al modelo del laissezfaire, sino que se espera de él la promoción del wellfare de los súbditos. «Por seguridad no debe aquí entenderse una mera preservación, sino también todas las demás satisfacciones

${ }^{45}$ T. HOBBES, Leviathan, op. cit., XXI, $\$ 22$.

${ }^{46}$ T. HOBBES, Elementos, op. cit., II, V, $\$ 1$. 
de la vida que cada hombre, mediante un legítimo trabajo, y sin peligro o daño para el Estado, adquiera para sí» ${ }^{47}$. Por tanto, si la obediencia en la sociedad civil es una combinación de deber y miedo, la divergencia de los intereses del soberano y los súbditos tiene como límite el que los súbditos sigan pensando que están más seguros bajo la protección soberana. Sin dicha protección, no sólo desaparece el deber, sino que a medio o largo plazo también desaparece el miedo. Ante la falta de convergencia entre los intereses mutuos de los súbditos y el soberano el único medio para mantener la obediencia ya no es el miedo, sino el terror y este no puede evitar por un lapso de tiempo prolongado la vuelta al estado de naturaleza o, mejor dicho, de guerra. «Y los fundamentos de estos derechos [esenciales del soberano] necesitan ser enseñados con diligencia y con verdad; pues no pueden mantenerse recurriendo a ley civil alguna, o por terror a un castigo legal» ${ }^{48}$.

La segunda modulación al mito construido en torno a la figura de Hobbes conlleva admitir que éste no anula jamás la pregunta por la libertad. El hombre que ha decidido no moverse ha rendido parcialmente su libertad natural y está obligado a comportarse según los dictados del soberano, porque así él mismo lo ha consentido. En este caso, la compulsión es compatible con la libertad natural y corporal ${ }^{49}$. En cambio, pierde su libertad cuando advierte que esta compulsión se transforma en una coacción que le impide moverse o actuar más allá de lo acordado ${ }^{50}$. En este caso, habiendo perdido su libertad corporal el hombre recupera su libertad natural -i.e. autodeterminación de su derecho-, ya que este tipo de violencia no es compatible con la existencia del pacto político ${ }^{51}$. Las cadenas no sólo anulan la libertad corporal, sino también cualquier obligación precedente.

Es evidente, entonces, que la relación entre libertad y miedo que Hobbes establece, tanto en De cive como en Leviathan, no cambia radicalmente desde un punto de vista fáctico. En ambas obras el miedo sigue siendo el factor determinante que mueve a los hombres a la obediencia o a la desobediencia. La libertad que se intenta fundamentar en

\footnotetext{
${ }^{47}$ T. HOBBES, Leviathan, op. cit., XXX, \$1. Ver también Ibid., XXI, \$12; Tratado sobre el ciudadano, op. cit., XIII, $\iint 4,14$.

48 T. HOBBES, Leviathan, op. cit., XXX, $\$ 4$.

${ }^{49}$ F. HOOD, op. cit., 150-163.

50 A. G. WERNHAM, «Liberty and Obligation in Hobbes». En Hobbes Studies, ed. K. C. Brown, 117-39. Cambridge: Harvard University Press, 1965, 123.

51 A. BRETT, op. cit., 227-31.
} 
De cive y en Leviathan poco tiene que ver con la garantía máxima de una esfera de protección individual en referencia a la intervención del Estado. El bien más valioso que el autor intenta remarcar es la seguridad que proporciona el poder soberano del Estado para la búsqueda del well-being ${ }^{52}$. De ahí que el principal escollo para la libertad no sea la interferencia, sino la degeneración del poder político en la búsqueda del interés individual del soberano como hombre natural, olvidando el colectivo ${ }^{53}$.

La clave de la resistencia política se encuentra, entonces, en la deliberación del costebeneficio -i.e. calcular el poder y medir los daños- y no en la libertad formal que se le reconoce al individuo político. En última instancia, los límites artificiales -i.e. obligación por el consentimiento dado- no hacen imposible sino peligroso el movimiento más allá de la legalidad ${ }^{54}$. Así, lo que debieran perseguir los hombres, según la demostración que expone Hobbes, no son ideales fantasiosos de libertad garantizados por una determinada forma de gobierno, sino las concretas posibilidades de auto-preservación. Allí donde la preservación no corre peligro, es irracional buscar la resistencia. Esa irracionalidad no surge de considerar la mayor o menor libertad que un soberano concede a los súbditos, sino por un cálculo racional de medios y fines que, según Hobbes, siempre hace a los hombres conservadores.

A los argumentos aquí presentados se les podría objetar que el soberano no participa del pacto político. Esta circunstancia, junto con el carácter absoluto de su poder, hacen imposible, según Hobbes, presentar reclamos al soberano. Hacerse cargo al completo de esta objeción excede la posible extensión de este artículo que he dedicado a analizar la relación que establece el autor entre la libertad y el miedo, para luego ponerlo en referencia con la resistencia. Más, no supone una objeción menor y resulta necesario dejar apuntados algunos aspectos de la posible respuesta.

Para comenzar, habría de insistir en el argumento presentado más arriba según el cual aceptar la autoridad del soberano no excluye juzgar si el ejercicio de dicha autoridad es correcto. De esta manera, la inalienabilidad del derecho sobre la propia preservación configura un criterio para establecer lo que hay de correcto en ese ejercicio. En última

\footnotetext{
52 W. LETWIN, "The economic foundations of Hobbes's politics". En Hobbes and Rousseau: A Collection of Critical Essays, ed. M. W. Cranston, 143-64. New York: Anchor Books, 1972, 160-164.

${ }^{53}$ Y. C. ZARKA, "The Political Subject". En Leviathan After 350 Years, ed. T. Sorell y L. Foisneau. Oxford: Clarendon Press, 2004, 167-182.

${ }^{54}$ M. GOLDSMITH, op. cit., 24-39.
} 
instancia, afirma Hobbes, nosotros hacemos al Estado ${ }^{55}$. Esta artificialidad del cuerpo político lo hace diferente de los cuerpos naturales. El estado al ser obra de la voluntad de los hombres, estos tienen el conocimiento del hacedor ${ }^{56}$. El hombre adquiere un conocimiento ideal sobre el cuerpo político, en especial de la voluntad tácita del pacto político, ya que es el productor de sus propiedades ${ }^{57}$. De ahí que nadie mejor que el propio individuo para juzgar qué es aquello que lo lleva mejor a su preservación. En consecuencia, no hay incompatibilidad entre sostener que el soberano no pacta y que se le puede desobedecer o resistir, porque ni el poder absoluto del soberano ni la vulneración del pacto son la justificación de dichos actos. Éstos se fundamentan en un cálculo individual basado en la necesidad natural en el que se sopesa el coste de la obediencia y la resistencia. En otras palabras, entre las iniquidades del soberano y el peligro de volver a regirse por las normas de la guerra. «Porque cuando los hombres comparan el beneficio de la injusticia por ellos cometida con el daño que se derivará de la pena, por necesidad natural escogen lo que les parece mejor para ellos» ${ }^{58}$.

De este modo, el argumento hobbesiano independiza, desde un plano lógico, el derecho natural del soberano y el de los súbditos. Ambos disponen de la fundamentación necesaria para ejercitarse sin la necesidad de apelar a la existencia de un deber en la contraparte. Del mismo modo que la libertad natural de los súbditos es consistente con el derecho absoluto de los soberanos, la libertad del soberano no está limitada por el derecho absoluto e inalienable de los súbditos a auto-preservarse. Empero, aún cuando estos derechos no se limiten mutuamente, sí ejercen una limitación fáctica de poder el uno en el otro $^{59}$. Precisamente, dicha afectación mutua es lo lleva a sostener que Hobbes identifica una faz agonal en la vida social que trasciende a la celebración del pacto político.

\footnotetext{
55 T. HOBBES, «Six lessons to the professors of the mathematics», en English Works, op. cit., VII, pp. 183-4. Ver también Leviathan, op. cit., XX, $\$ 19$.

${ }^{56}$ Ver T. HOBBES, «De Corpore», en English Works, op. cit., I, I, \9.

${ }^{57}$ T. SORELL, «Descartes, Hobbes and the Body of Natural Science». Monist 4 (71): 515-525.

${ }^{58}$ T. HOBBES, Leviathan, op. cit., XXVII, $\$ 8$.

${ }^{59}$ Ver T. SORELL, "The Burdensome Freedom of Sovereigns". En Leviathan After 350 Years, ed. T. Sorell y L. Foisneau. Oxford, Clarendon Press, 183-196.
} 


\section{Consideraciones finales}

En la introducción del artículo se plantean dos interrogantes. ¿Cuál es el espacio para libertad del hombre en el pacto político hobbesiano? ¿Es la resistencia política presentada en el Leviathan un artilugio retórico carente de vocación de facticidad o, por el contrario, es la tangente de fuga de un discurso sobre el poder que tiende a encerrarse en un argumento circular? De la argumentación presentada en el artículo se desprenden las respuestas.

En primer lugar, Hobbes no niega la determinación que el miedo ejerce sobre la voluntad. Sin embargo, también sostiene que la decisión informada por el miedo sigue siendo libre porque no se orienta siempre y en todo momento hacia el mismo lugar. Las circunstancias varían, al igual que la vida misma es movimiento. Tanto en el estado de naturaleza como en la sociedad civil, no existe algo como una decisión final, irrevocable y ajena a la influencia de las nuevas circunstancias futuras. Por lo tanto, el miedo no puede constreñir la capacidad de movimiento del hombre, y así su libertad, al punto de que no pueda renovar la guerra si surgiera «alguna nueva y justa causa de temor» ${ }^{60}$. De esta manera, la compatibilidad entre miedo y libertad no significa que el hombre esté determinado irracionalmente a aceptar someterse a una voluntad ajena que sólo busca expoliarlo. Incluso en un Estado «en el que el poder soberano es adquirido por la fuerza», los hombres esperan poder salvar sus vidas y libertades ${ }^{61}$. La defraudación de dicha esperanza hace que el consentimiento dure lo mismo que tarda un número considerable de hombres en darse cuenta de que han sido engañados, y que su mismo número les da la fuerza para liberarse.

En segundo lugar, aún cuando difícilmente pueda sostenerse que Hobbes hubiese apoyado una acción de resistencia política concreta, esto no contradice que su teoría de la obediencia a cambio de seguridad necesite de la desobediencia o la resistencia política como un corolario lógico a su argumentación. De este modo, parte de la contribución hobbesiana a la fundamentación del estado sería distinguir el poder soberano absoluto, de uno que se pretenda arbitrario y eterno. De ahí que los defensores del absolutismo de origen divino encontraran en la obra de Hobbes un auténtico catecismo subversivo. Por

\footnotetext{
${ }^{60}$ T. HOBBES, Leviathan, op. cit., XIV, $\$ 27$.
}

${ }^{61}$ Ibid., XX, $₫ \S 1-2$. 
ejemplo, Bramhall afirmó que «no hay necesidad de ningún otro fuelle para avivar el fuego de una guerra civil, y poner en convulsión a todo un Estado, que este artículo sedicioso [...] ¿Porque no habríamos de cambiar el nombre de Leviathan por Catecismo de los Rebeldes?» ${ }^{62}$. Sin entrar en detalle en la recepción calidoscópica de la filosofía política hobbesiana, esta breve nota ha de servir, al menos, para ponernos en guardia y precavernos de una lectura lineal y literal de un texto complejo y profundo cuya ramificaciones se extienden a lo largo de toda la obra del autor. Así, mientras se reconozca la infructuosidad de la pretensión de abortar la faz agonal de la vida política tal como la describe Hobbes, la resistencia no sólo es una realidad fáctica, sino también es una pieza necesaria -al menos potencialmente- del sistema político descrito en el Leviathan.

Esta lectura de la obra de Hobbes no pretende ser vindicativa, ni ocultar el carácter conservador del autor. Es imposible soslayar que, según el autor, si no hay mayor libertad que el verse libre de los impedimentos para buscar la auto-preservación, la decisión más racional debería ser «[...] disfrutar de la situación presente, aunque no fuera la mejor, a que mediante una guerra, y ya muchos muertos vosotros o decrépitos, otros hombres u otros tiempos tuvieran un estado de cosas reformado» ${ }^{63}$.

En este sentido, la filosofía hobbesiana funciona, más allá de la intencionalidad primera del autor, como un espejo que refleja el límite de los sistemas políticos occidentales. Tal como señala el etnólogo Pierre Clastres, que un espejo no nos devuelva más imagen que a nosotros mismos no implica que no haya nada para observar. En este caso, la obra del autor inglés muestra la imagen de una sociedad en la que el límite de la libertad no es tanto el poder, sino la satisfacción individual. El Leviathan es un panegírico de la satisfacción que busca hacer evidente a los ciudadanos ingleses del siglo XVII que la libertad como móvil principal de la resistencia funciona como un galimatías. Es decir, que allí donde sus necesidades individuales se encuentren satisfechas -sin cuestionar la autenticidad de dichas necesidades- no hay ni oportunidad fáctica ni legitimidad racional para la resistencia política.

Empero, este individualismo conservador de Hobbes no restringe, tampoco, una lectura que encuentre en las acciones colectivas una vía para la recuperación del hombre como ciudadano. La resistencia política, al igual que el pacto político, aún cuando se

\footnotetext{
${ }^{62}$ J. BRAMHALL, "Catching of Leviathan", op. cit., 145 [traducción propia].
}

${ }_{63}$ T. HOBBES, Tratado sobre el ciudadano, op. cit., 54-55. 
funde en derechos individuales, sólo acontece allí donde se produce la conformación de una voluntad colectiva. Queda para futuras indagaciones explorar esta lógica implícita al contractualismo hobbesiano que encuentra en el individuo un actor político que, de forma necesaria, opera colectivamente. En última instancia, aún cuando de las obras de Hobbes se desprenda el arqueológico antecedente de la afirmación marcuseana de la libertad es el yugo de la libertad, es difícil sostener que el inglés haya llegado a avizorar la posibilidad externa de clausurar los espacios interiores de libertad. En definitiva, su teoría de la libertad gira, de forma permanente, tal como se ha argumentado en este artículo, en torno a la convicción de que ese fuero interno es un parapeto infranqueable para el poder soberano. 